\title{
LA TEORÍA DE LA VOLUNTAD DE JOSÉ EUSEBIO CARO: EL CONCEPTO DE HOMBRE EN EL PENSAMIENTO COLOMBIANO DEL SIGLO XIX Y SU RELACIÓN CON LA FILOSOFÍA LIBERAL FRANCESA*
}

\author{
RubÉn GÉLVEZ HiguerA ** \\ doi: 10.11144/Javeriana.uph37-75.tvjc
}

\section{RESUMEN}

En 1836, a los 19 años, el filósofo colombiano José Eusebio Caro compuso un tratado sociológico y antropológico titulado Mecánica social, en el que se muestra en contexto la acogida que tuvo la filosofía francesa (sensualismo, ideología y fisiología) en el pensamiento colombiano del siglo XIX. El propósito de este artículo es exponer críticamente la teoría de la voluntad diseñada por José Eusebio Caro en dicha obra y, en conjunto, poner en evidencia las fuentes filosóficas en las que se apoyó, particularmente la fisiología y su papel como base teórica tanto para la ideología como para la construcción de una novedosa "antropología científica”, sobre la cual se fundamenta la ciencia de la moral y la legislación, objetivos propios del pensamiento liberal radical francés.

Palabras clave: ideología; sensualismo; liberalismo radical; fisiología; mecanicismo

Artículo resultado de la beca de investigación Revisión crítica de la memoria bibliográfica, otorgada por el Instituto Caro y Cuervo y el Ministerio de Cultura de la República de Colombia, 2012-2013.

Universidad Católica de Colombia, Bogotá, Colombia.

Correo electrónico: crgelvez@ucatolica.edu.co

Para citar este artículo: Gélvez Higuera, R. (2019). La teoría de la voluntad de José Eusebio Caro: el concepto de hombre en el pensamiento colombiano del siglo XIX y su relación con la filosofía liberal francesa. Universitas Philosophica, 37(75), 123-149. ISSN 0120-5323, ISSN en línea 23462426. doi: 10.11144/Javeriana.uph37-75.tvjc 


\title{
J. E. CARO'S THEORY OF THE WILL: THE CONCEPT OF MAN IN $19^{\mathrm{TH}}$-CENTURY COLOMBIAN THOUGHT AND ITS NEXUS WITH FRENCH LIBERAL PHILOSOPHY
}

\begin{abstract}
In 1836, at 19 years of age, Colombian philosopher José Eusebio Caro wrote a sociological and anthropological treatise titled Mecánica social (Social Mechanics) that illustrates in context the reception of French philosophy (sensualism, ideology, physiology) in $19^{\text {th }}$-century Colombian philosophical thought. The purpose of this paper is to present critically Caro's theory of the will and to bring to light the philosophical sources from which he draw, especially physiology and its role as theoretical basis for both ideology and a new "scientific" anthropology that could, in turn, provide support for a science of morals and legislation, a major goal of French radical liberal thought.
\end{abstract}

Keywords: ideology; sensualism; radical liberalism; physiology; mechanicism 


\section{Introducción}

RESPECTO DE LOS FUERTES CAMBIOS CONCEPTUALES implicados por el proceso de Independencia, Steinar Saether (2005) formula la siguiente pregunta:

¿Tuvo algún impacto la nueva forma de conceptualizar la sociedad en la vida de los hombres y mujeres corrientes a lo largo de América Latina, o la nueva sociedad era en gran parte algo que existía únicamente en las mentes de un grupo exclusivo de personas letradas con acceso a medios literarios? (p. 28)

La pregunta resume el cuestionamiento que Saether le hace a la célebre tesis de François-Xavier Guerra según la cual el rasgo más evidente de revoluciones como la Francesa o la de Independencia latinoamericana consiste en "la conciencia que tienen los actores, y que todas las fuentes reflejan, de abordar una nueva era, de estar fundando un hombre nuevo, una nueva sociedad y una nueva política" (Guerra, 1993, p. 13, citado en Saether, 2005, p. 27).

Guerra (1993) expone claramente que, en efecto, al hablar de los actores principales del proceso revolucionario que elaboran y -en sus términos- "imponen" el nuevo "sistema de referencias" (hombre-sociedad-política), está pensando en "nobles y patricios, clérigos, profesores y estudiantes, empleados públicos [...]; todo un conjunto de hombres cuyo rasgo común no es una común situación socioeconómica, sino su pertenencia al mismo mundo cultural” (p. 14). Esto es, las "personas letradas" de Saether.

Ensanchando su tesis, afirma Guerra (1993) que "toda relación social posee un contenido cultural fundamental: ¿cómo está pensada o imaginada la sociedad? ¿Qué es lo que constituye el vínculo social?’. Como respuesta a estas preguntas, asegura que "toda organización social lleva también consigo, aunque solo sea implícitamente, un modelo de sociedad ideal que puede situarse tanto en el pasado como en el futuro: que puede ser tanto una nostalgia como un proyecto [...]" (p. 15). Al invocar la "organización social", Guerra (1993) estaría incorporando a "los hombres y mujeres corrientes", precisamente en el entendido de que, en su concepto, lo "radicalmente nuevo" de estas revoluciones de los siglos XVIII y XIX no es

[...] la existencia de un nuevo sistema global de referencias en el que se combinan las ideas, imaginarios sociales, valores y comportamientos que deben 
configurar al nuevo hombre y a la nueva sociedad [...]. Lo radicalmente nuevo es la creación de una escena pública cuando este nuevo sistema de referencias deja los círculos privados en los que hasta entonces había estado recluido, para irrumpir a plena luz (p. 13).

Ahora bien, citamos este pequeño debate ante la necesidad de advertir que hay en ambos autores una enorme cantidad de elementos filosóficos que, al darse por sentados, terminan pasándose por alto. En el caso de Guerra, creemos que es acertada la consideración de que toda relación social posee un contenido cultural, pero este no puede ser fundamental, porque estaríamos asumiendo que la cultura o el "sistema global de referencias" existe previamente y como condición de posibilidad de la relación social. Hablamos aquí de esa suerte de gran cultura como sistema coherente que normaliza, habitúa o regulariza las conductas individuales (Bauman, 2002, p. 27). Gran cultura a la que paradójicamente una cultura (esto es, un "nuevo sistema de referencias") se resiste, desestabiliza y termina por subvertir hasta consolidarse como otra gran cultura, fenómeno que de todas maneras asume ambas culturas como algo dado. Y nótese que esta idea de la gran cultura es la que lleva a Guerra, por un lado, a afirmar que los autores de la revolución cultural tienen "plena conciencia" de estar fundando un nuevo hombre, una nueva sociedad y otra política, y también a Saether, por otro, a considerar como problemático asignarle una autoría a la nueva conceptualización de la sociedad, es decir, la tesis de que esta existe solo en la mente de un grupo exclusivo de personas. Para ambos, la cultura se explica por la cultura misma.

No es un objetivo de este artículo debatir el concepto de cultura, cuya polisemia es sumamente problemática y sobre el cual existe una literatura abundante. El debate citado simplemente deja al descubierto ciertas grietas, entre las cuales consideramos hay una veta que sería interesante seguir. Asumiendo la propuesta metodológica expuesta por el propio Saether (2005), quizá sea más fructífero limitar las macroteorías por medio de la "realización de estudios locales y regionales" (p. 29). Él se refiere, claro está, a un aspecto geográfico, pero en nuestro caso se trataría de un problema histórico particular: el de la construcción de ese "nuevo sistema global de referencias" al que Guerra le adjudica la configuración del nuevo hombre y la nueva sociedad en los siglos XVIII y XIX; novedades que trae consigo tanto la Revolución francesa como la Independencia latinoamericana. Es difícil comprender el orden de los factores aquí, pues no sabemos si son 
las revoluciones las que conllevan esta construcción teórica como novedad, o es esta novedad la que desencadena la revolución. Según Guerra (1993), la primera opción resultaría más plausible puesto que, para él, la "Ilustración -Modernidadno implica necesariamente la revolución” (p. 20).

El supuesto principal del texto de Guerra es que el "sistema global de referencias", esto es, la triada de conceptos hombre-sociedad-política es complejo conceptual homogéneo. Los conceptos se implican unos a otros, ya que los actores revolucionarios son promotores conscientes de estas novedades en el espacio y el discurso públicos. Pero podemos aventurar la hipótesis de que históricamente ciertos conceptos teóricos, más que implicarse lógicamente en un complejo conceptual, tienden a modificarse y, de esta suerte, a hacerse incompatibles en un entramado teórico que busca la homogeneidad. En concreto, como lo muestra Renan Silva (2008) en el caso colombiano, la importancia que empieza a tener la filosofía natural en los círculos ilustrados conduce a una modificación del concepto de hombre en el entendido de que este tiene ahora "la capacidad infinita [...] para arrancar sus secretos a la naturaleza” (p. 57). Más aún, Mutis ya empezaba a tomar en consideración una idea que Silva considera inédita para la época: el carácter social de los conocimientos científicos, en el entendido de que para el sabio cualquier hombre "de cualquier condición y estado" (p. 58) tenía la posibilidad de aplicarse al estudio de las ciencias útiles. Por otro lado, y situándonos algunas décadas adelante de las guerras de Independencia, la introducción y difusión de la filosofía liberal francesa e inglesa en Colombia implican también la modificación teórica del concepto de hombre, por su fuerte sujeción al al método experimental, que exigía sumar a la definción del hombre como sustancia pensante las particularidades de su fisiología (J. E. Caro, 2002). Todo esto sumado a la guerra que ciertos pensadores franceses le declararon a lo que denominaron el "pensamiento de sistema" (C. Comte, 1836, vol. I, p. 8).

La modificación del concepto de hombre modifica a su vez otro gran concepto: el de la moral. De esta suerte, la triada hombre-sociedad-política en cuanto complejo conceptual pasa a considerarse en el siglo XIX como objeto de un campo de estudio llamado ciencia de la moral y la legislación. Esta ciencia tiene como propósito encontrar las leyes que regulan el "movimiento" progresivo del hombre como sujeto moral fisiológico y así de la sociedad como "conjunto de hombres" (C. Comte, 1836, p. 43). Vemos que los conceptos de hombre y de moral obligan 
a modificar el de sociedad. Todo este aparataje teórico obedece, y en esto tiene razón Guerra, a un proyecto de sociedad sustentado en eso que Silva (2008) llama los “ideales de la Ilustración" (p. 27): la prosperidad, la riqueza y la felicidad.

Ahora bien, a pesar de los intentos por hacer caber todos estos conceptos en un cuerpo teórico homogéneo llamado ciencia de la moral y la legislación -homogeneidad que sería lograda ajustándose al método de las ciencias experimentales y no a la lógica interna de un sistema racional-, el caso particular del pensador colombiano José Eusebio Caro y su obra de juventud titulada Mecánica social evidencia las dificultades de tal empresa. Y es aquí donde, de nuevo siguiendo el método de Saether del estudio local y regional, encontramos la veta principal.

\section{José Eusebio Caro y la filosofía francesa}

RESULTA INTERESANTE CONSTATAR que respecto de la difusión de la filosofía francesa en Latinoamérica en el siglo XIX, impulsada como política educativa por los gobiernos de la época (Bushnell, 1985), los estudios generales sobre las ideas filosóficas (Larroyo, 1989; Jaramillo, 2001; Beorlegui, 2006; Dussel, Mendieta \& Bohórquez, 2011) no suelen explicar en contexto de qué tipo de filosofía se trata ni cuáles son sus alcances teóricos, más allá de algunas menciones antológicas y en todo caso esquemáticas que en no pocas ocasiones confunden doctrinas y escuelas. Responde esto, quizá, a la manera en que se subestima (no sin razones, en ciertos casos) tanto a ciertos pensadores latinoamericanos como a la propia filosofía francesa en el siglo XIX, juzgada, incluso en Francia, de no ser más que un comentario a la filosofía crítica de Kant (Lefranc, 2011).

El borrador de la Mecánica social es esclarecedor, ya que escapa a todas las categorías históricas con las que usualmente se ha clasificado el pensamiento de José Eusebio Caro, autor que, dependiendo del estudio del que se trate, recorre un enorme y abigarrado espectro intelectual: desde el neotomismo, el romanticismo y espiritualismo cristiano, hasta el benthamismo y el positivismo. Pero, curiosamente, en los estudios generales mencionados no se vincula a Caro con los ideólogos franceses, su mayor influencia de juventud, ni, con la excepción de Jaime Jaramillo Uribe, con el pensamiento liberal, con el que fue educado en su época de estudiante.

Caro compuso la Mecánica social en 1836, a los 19 años, con las herramientas teóricas de las que disponía un estudiante del colegio San Bartolomé de la época: 
el utilitarismo de Bentham y el sensualismo de Condillac -obligatorios en el plan de estudios del general Santander (López, 1990)-; y la ideología de Tracy, Volney y de Biran, complementadas con las tesis de los "fisiologistas" (Brussais, Cabanis), como los llama el propio Caro (1873), y las doctrinas políticoeconómicas de los liberales franceses de principios del siglo XIX (Say, Bastiat, Constant, Charles Comte). Respecto de la filiación de Caro al positivismo de Auguste Comte, ya tuve la oportunidad de desmentirla en otro artículo (Gélvez, 2017), por lo que tal referencia no será tenida en cuenta aquí en lo que concierne a la Mecánica social.

El propósito de este artículo es, por tanto, exponer la teoría de la voluntad diseñada por José Eusebio Caro en la Mecánica social y al mismo tiempo ir desentrañando sus referencias filosóficas, de suerte que pueda ser apreciada en contexto la manera en que el autor se apoyó en el pensamiento francés y su promesa de ofrecer herramientas teóricas con las cuales, gracias al nuevo concepto de hombre y de moral, sustentar la organización de aquella sociedad decimonónica que se desprendía del Antiguo Régimen. Es objeto de este artículo, también, llamar la atención respecto del papel de la fisiología y del mecanicismo como contexto teórico del pensamiento filosófico tanto colombiano como francés en el siglo xIx.

\section{El punto de partida: el movimiento}

Afirma José Eusebio Caro (2002, pp. 239-240) que un debate entre los estudiantes de legislación del colegio San Bartolomé y su profesor, el doctor José Ignacio de Márquez, en relación con la aparente contradicción entre acciones juzgadas como malas pero cuyo efecto no son penas, como reza la ética utilitarista de Bentham, fue el motivo que lo impulsó a desarrollar una ciencia de la moral y la legislación bajo el título de Mecánica social. Caro se propone con su escrito fundamentar una "ciencia" y no componer un tratado filosófico, puesto que el ataque al pensamiento de "sistema" atribuido a la filosofía especulativa era característico del pensamiento liberal francés de la época. De tal suerte, advierte Caro que quienes lean su obra no deben buscar en ella máximas o demostraciones, sino hechos comprobables. En el capítulo I del Libro V, folio 160v, titulado "Objeto de este libro. Plan que en los libros anteriores he trazado", afirma José Eusebio Caro (2002): "Yo me he propuesto observar los hechos, observar sus 
causas, observar la filiación entre los hechos y estas causas, observar sus efectos, observar la filiación entre los hechos y estos efectos. Como Say, no me he propuesto probar sino descubrir (pp. 239-240)"1.

Observar los "hechos", determinar su naturaleza, sus causas y sus efectos es el método que asume Caro como eje teórico de su escrito. Tanto dicho método como los postulados generales de su obra los tomará de un filósofo liberal francés que no es mencionado en prácticamente ninguno de los estudios ya citados sobre el pensamiento filosófico latinoamericano en el siglo XIx: se trata de Charles Comte ${ }^{2}$. En su Tratado de legislación o exposición de las leyes generales con arreglo a las cuales prosperan, decaen o se estancan los pueblos, publicado por primera vez en Francia en 1826, Comte (p. 279) bautiza aquel como método analítico ${ }^{3}$ y expone el que será el hecho fundamental para la ciencia de la moral y la legislación: el movimiento. Caro (2002) abre de igual manera su obra con la pregunta por el hecho más simple que es susceptible de ser observado en la sociedad humana, y su respuesta da título al capítulo primero del libro I de la Mecánica social: "Primer hecho: El hombre en movimiento" (p. 123). El movimiento es un hecho generalizado que puede encontrarse tanto en el hombre como en la sociedad, definida esta como "colección de individuos" y aquel como "colección de miembros" (p. 128). El matiz fisiologista de esta nueva antropología se hace evidente. Caro concluye: "hombre inmóvil no es hombre, es cadáver. Sociedad inmóvil no es sociedad, es cementerio. Luego el hombre, como hombre, supone el movimiento” (p. 133).

1 Textualmente, Say (1816) afirma: “así, en la economía política como en la física y en todos los demás ramos de nuestro conocimiento, se han formado los sistemas antes de conocerse las verdades, porque es mucho más fácil forjar un sistema, que descubrir una verdad" (pp. LXX-LXXI). Esta postura podría pasar como positivista, pero hay que hacer mucho énfasis en que la apelación a los "hechos" no es en absoluto un principio original de la filosofía de Auguste Comte, quien también la heredó.

2 Jaime Jaramillo Uribe (2001, p. 110) alcanza a hacer una muy breve referencia al nombre de Charles Comte, entre otros escritores franceses, como fuente teórica de los políticos neogranadinos hacia 1850 respecto del problema de la legislación y la organización jurídica de la república, pero sin establecer vinculación alguna entre este y José Eusebio Caro.

3 Este método analítico ya había sido utilizado por Condillac para referirse al estudio del origen de las ideas, el cual fue llamado sensualismo a partir del siglo xIx por sus seguidores y detractores. De Tracy lo nombró ideología, dado que su teoría se basaba en el "análisis de las sensaciones y las ideas". Véase Lefranc, 2011, p. 8. 
El principio del movimiento hace parte también del cuerpo teórico de los ideólogos. Al respecto dice Cabanis (1826): "todo en la naturaleza está en movimiento; todo es descomposición y recomposición, destrucción y reproducción perpetua" (p. 54). Broussais (1827), sumando el análisis fisiológico, afirma:

La composición de los órganos y de los fluidos es una química particular del ser viviente. La potencia que pone en acción esta química da a los órganos al componerlos la facultad de sentir y moverse contrayéndose. La sensibilidad, pues, y la contractilidad, son los testimonios o las pruebas del estado de vida (p. II).

Siendo el movimiento el hecho fundamental para la ciencia de la moral y la legislación, el análisis de su "naturaleza" es el primer paso según el método analítico expuesto por Charles Comte. Ahora bien, la respuesta a la pregunta sobre por qué se parte del movimiento y qué se intenta con la fundamentación de una "ciencia" como la mencionada, la ofrece el propio escritor francés:

El efecto de la aplicación del método analítico al estudio de la moral y la legislación es el de impulsar la acción de la mayor parte del género humano a proscribir los hábitos o instituciones que le son funestas, y a multiplicar o establecer los hábitos o la instituciones que le son beneficiosas. Dado que los hombres tienden naturalmente a su conservación y desarrollo, el análisis tiene por efecto hacerles ver la ruta que deben serguir y aquella que deben evitar. (Comte, 1826, p. 75)

La pretensión de la ciencia de la moral y la legislación es mostrar la ruta que la sociedad debe seguir para alcanzar naturalmente su desarrollo, entendiendo como natural la supresión de "malos" hábitos e instituciones y la multiplicación de los "provechosos". La moral y la ley están profundamente unidas, en tanto que la primera sustenta la segunda, pero bajo la premisa de que es letra muerta aquella legislación que no tenga en cuenta una conducta humana que persigue objetivos que los teóricos de la época, tanto ingleses como franceses, con bastante

4 «L'effet de l'application de la méthode analytique à l'étude de la morale et de la législation, est de déterminer l'action de la plus grande partie du genre humain, à proscrire les habitudes ou les institutions qui lui sont funestes, et à multiplier ou à établir les habitudes ou les institutions qui lui sont avantageuses. Les hommes tendant naturellement vers leur conservation et leur développement, l'analyse a pour effet de leur faire voir quelle est la route qu'ils doivent suivre et quelle est celle qu'ils doivent éviter. » 
ingenuidad consideraron sencillos: acoger placeres y evitar penas. Soportan tales consideraciones la inmadurez de una fisiología en ciernes, el contexto mecanicista de la filosofía y el desprecio de los ideólogos por la psicología, a la que consideraban una doctrina metafísica (Lefranc, 2011). El resultado es un juicio moral que sufre un vuelco radical, pues la moralidad pierde la potestad de juzgar a prio$r i$ los actos. Según el utilitarismo, lo que hace a un acto moralmente bueno son sus efectos y -particularmente en el pensamiento de Caro- la acertada puesta en marcha del mecanismo de la voluntad.

La difusión de la filosofía francesa en el pensamiento latinoamericano, a despecho de la alemana, se explica, entre otras causas, porque ofrece un sustento teórico sencillo y plausible para su época, precisamente por su recurso a la fisiología humana, y de amplio alcance político, sobre el cual sustentar la reestructuración profunda de todo ese aparato social que se despide de la monarquía. Dicha reestructuración no debe empezar por las instituciones de gobierno, puesto que estas se enfrentan al problema de la aplicación de leyes que chocan con las costumbres de una sociedad atada al Antiguo Régimen (Sosa, 2006; Guerra, 1993). Ha de empezar por la antropología, por la redefinición del hombre mismo, pues es su reunión (la "colección de individuos") la que teóricamente constituye la sociedad. La teoría juega un papel importante en este momento histórico, pues la sociedad de individuos es un concepto sumamente abstracto y de difícil comprensión frente a la sencillez semiótica del corpus mysticum politicum. La referencia al individuo humano, sin duda, facilita las cosas: la sociedad es un "hombre grande". Hay que comprender el comportamiento humano singular para poder entender cómo se comporta la sociedad en general y desde allí construir las instituciones que, como reza el utilitarismo, sean más expeditas para lograr la felicidad de la mayoría. Por supuesto, no notan los filósofos franceses liberales que están partiendo de un principio indemostrable que contradice sus propios postulados empíricos: el del progreso natural indefinido o principio de perfectibilidad de la sociedad humana. Incluso Auguste Comte, en su teoría de los tres estados, desaprobó dicho principio5.

5 'La imperfección de la lengua me obliga a emplear esas palabras, 'perfeccionamiento' y 'desarrollo', de las cuales la primera, e incluso la segunda, aunque más precisa, recuerda ordinariamente las ideas 
Por todo esto, es verdaderamente interesante constatar que Caro advierte de entrada la inutilidad filosófica del análisis de la "naturaleza" del movimiento humano. El autor plantea el análisis bajo el siguiente esquema aristotélico:

Antes de comenzar a hacer la clasificación del movimiento humano, es necesario formarnos una idea clara de los principios que en esta clasificación van a conducirnos.

Clasificar, no es más que distribuir en clases; distribuir en clases no es más que distribuir en clases diferentes; distribuir en clases diferentes no es más que observar, entre individuo e individuo de los que componen cada clase, semejanzas, entre clase y clase de las que componen el todo, diferencias: de manera que, contrayéndonos al propósito de que nos ocupamos, clasificar los movimientos humanos no es más que separar en clases distintas todos los movimientos que se diferencian; a la vez que se van dejando reunidos en cada clase todos los movimientos que se asemejan.

Así, clasificar, es a un tiempo reunir y separar, asemejar y distinguir, componer y descomponer (Caro, 2002, pp. 141-142).

Caro realiza un extenso examen a lo largo de tres capítulos, en el que intenta clasificar el movimiento humano por semejanzas y diferencias -absolutas, relativas, de grado- y también por sus propiedades. A las primeras responde: "el principio de clasificación por diferencia relativa no puede seguirse. La clasificación de todos los movimientos humanos por razón de sus diferentes grados no puede completarse" (Caro, 2002, p. 161). La búsqueda de propiedades naturales en el movimiento humano, el acto, le resulta infructuosa porque, primero, no hay una acción idéntica a otra de la que pueda extraerse una propiedad esencial comparativa y, segundo, el "movimiento" no es un "ente" con propiedades. Precisamente, sobre las acciones en cuanto hecho fenoménico afirmará Caro (2002): "un hecho puede producir otro hecho semejante, pero no algo material” (p. 201).

En el libro I, titulado "Naturaleza de las acciones", capítulo II, titulado "Clasificación de las acciones humanas", con rigor lógico concluye:

del bien absoluto y del mejoramiento indefinido, que no tengo en modo alguno la intención de expresar" (Comte, 2001, p. 264). 
Necesidades de hacer una clasificación completa de las acciones. Dificultades que se presentan -son innumerables-. No hay una acción idéntica a otra. Imposibilidad de hacer una buena clasificación tomada de su naturaleza misma. Pudieran dividirse: por la figura que describen; por su velocidad; por su fuerza; por su duración; por los objetos sobre los cuales se producen [...]; por los músculos que las producen: en internas y externas [...]; todas estas clasificaciones son inútiles. No conducen a nada. No enseñan nada (Caro, 2002, pp. 174-175).

\section{La voluntad: causa del movimiento humano}

Caro aVEntura, entonces, un nuevo análisis del movimiento humano a partir de sus causas y sus efectos; un tipo de análisis que, por cierto, constituye el segundo paso del método analítico. Propone clasificar las acciones en espontáneas y no espontáneas, según sus causas. Para él, las causas de las acciones no espontáneas son las causas generales de todo movimiento -aquí pensado desde la física; el movimiento de los cuerpos es no-espontáneo porque tiende a la inercia-:

Puesto un cuerpo en quietud, su inercia consiste en la necesidad, que tiene para moverse, de que una causa extraña lo mueva, pues por sí mismo, él no se mueve. La inercia del cuerpo inmóvil produce la impulsión en el instante del movimiento, una resistencia a la causa extraña que le da impulso.

La voluntad tiene este poder. La inercia de un cuerpo en movimiento consiste en la necesidad de una causa extraña que le detenga, pues por sí mismo él no se detiene. Y no solo necesita una causa extraña que le detenga, sino que ofrece una resistencia al influjo de esta causa. El cuerpo humano en esta materia está en el mismo caso que cualquier otro cuerpo (Caro, 2002, p. 267).

Las causas de las acciones espontáneas son o bien la mecánica vegetal y animal (es decir, el movimiento orgánico natural o el movimiento instintivo), o la voluntad. Esta "obra activamente tanto para producir el movimiento y continuarle, como para suspenderle y aun a veces, hasta para continuar la suspensión" (Caro, 2002, p. 267). La voluntad es, entonces, esa causa extraña que mueve al cuerpo humano en tanto este, en su naturaleza, no encierra "razón alguna para moverse en una dirección, con una velocidad, en una época, más bien que en otra 
época, con otra velocidad, en otra dirección” (p. 267). Esto es posible gracias a un poder material que ostenta la voluntad. También, en su opinión, la voluntad ostenta un poder inmaterial, pero esta parte Caro la dejó inconclusa.

Respecto del movimiento humano, y desde el punto de vista del método analítico, la causa del movimiento humano espontáneo, es decir, de las acciones, es la voluntad. Ella se "descubre" en cada uno a partir de la observación y experiencia propias y en los "otros" por analogía fisiológica con el sujeto individual. La influencia en Caro del pensamiento de Broussais, de Cabanis, de Destutt de Tracy y de Maine de Biran, autores todos citados en la Mecánica social, es evidente en este análisis.

Cabanis (1815, p. lxxxix) afirma que es en el cerebro, órgano central, en el que reside la voluntad general. Desde la fisiología, asegura Broussais (1827):

XVI. La acción mandada por el centro cerebral de relación se ejecuta por medio del aparato muscular locomotor, que está a las órdenes del cerebro; y los mismos nervios que han servido a conducir la impresión, sirven para ejecutar las voluntades del centro de percepción por parte de su tejido, que comunica con los músculos locomotores (p. IV).

Para de Tracy (1804, p. 73), en el entendido de que es la voluntad la encargada de dirigir los movimientos de los miembros y las operaciones de la inteligencia, sus efectos son justamente la base de cualquier estudio ético, toda vez que la ética es concebida como el estudio del origen de los deseos, elemento importante en la mecánica de la acción moral (Copleston, 2004, t. IV, p. IX-23) ${ }^{6}$.

\section{La voluntad y el yo (moi)}

EN El PRIMER CAPÍTUlo del libro I de la primera parte de la Mecánica social, José Eusebio Caro (2002) había adelantado la teoría de los círculos concéntricos de relaciones personales de Helvecio ${ }^{7}$. Allí había puesto de relieve que el centro

6 Se cita acá el compilado en cuatro tomos de los nueve originales de la Historia de la Filosofía de Copleston. Dado que el libro no tiene una numeración continua, el numero en romano remite al tomo original y el arábigo a la página del libro.

7 Según Caro, Helvecio, el "Newton de la moral y la legislación", habría descubierto la atracción universal de los individuos, es decir, una red de relaciones sociales concéntricas en las que el interés, entendido como una fuerza análoga a la gravedad, dirigiría la acción moral "en razón de las masas 
del círculo social es el yo. "El que no conoce su yo, no existe", afirma (p. 130). Si existir significa conocer el yo, y la existencia, esto es, la vida, se identifica con el movimiento, es el movimiento en el ser humano el elemento que permite conocer el yo.

Pero el yo interior no solamente se conoce por medio del movimiento. Bajo influencia de Cabanis $(1826)^{8}$, De Tracy señala la necesidad de la movilidad o motilité para conocer el mundo exterior; por medio de la acción voluntaria, el yo choca con el mundo y encuentra "resistencias" que evidencian un "algo" afuera, el mundo, pero que, sobre todo, le permiten percibir un "algo" adentro, el yo (p. 37).

Respecto de la percepción, el movimiento y el yo en cuanto elementos del mecanismo fisiológico, dice Broussais (1827):

XV. Todo estímulo capaz de procurar al cerebro una percepción, recorre todo el conjunto del sistema nervioso de relación [...].

XXXIII. Solicitado el centro de relación por la influencia de las vísceras, excita con el concurso de la voluntad, o sin él, con la consciencia del Yo, o sin ella, en el aparato locomotor movimientos que están en razón directa de las irritaciones viscerales, y que tienen por término la cesación de estas irritaciones, o bien la obstrucción, la compresión, o, en fin, la desorganización del cerebro.

XXXIV. [...] Los fenómenos que dan la idea del Yo no son pues continuos, mientras que la percepción y la reacción del centro de relación no se interrumpen jamás.

XXXV. Las percepciones del centro cerebral de que el Yo tiene conocimiento se llaman sensibilidad, y los movimientos que dirige se llaman voluntarios $[\ldots]$.

y de las distancias" que hay entre el agente de la acción y las personas a las cuales esta afecta. En la Mecánica social las masas equivaldrían al "valor del placer y pena y la sensibilidad de los individuos", clara referencia a Bentham, y las distancias al "grado de relaciones" respecto de personas consideradas muy cercanas al agente de la acción, como su familia y amigos, o muy lejanas, como sus compatriotas, congéneres o los animales. Según Caro (2002), "la mayor fuerza está en el centro", esto es, en el "interés personal" (pp. 217-218).

8 Es De Tracy quien realiza los resúmenes analíticos de la obra de Cabanis (1815). 
XXXVI. Siempre que el Yo tiene una percepción se siente al mismo tiempo en el cerebro y fuera de él [...] (pp. iv, viii y ix; énfasis añadidos).

De esta manera, según los ideólogos, las impresiones humanas se conciben como activas. Hay una suerte de "fenómeno interno" en la acción que interviene activamente en el conocimiento y formación de la consciencia del yo: la modificación (que será referida más adelante), y esto ocurriría en el hombre incluso desde la etapa fetal, según Cabanis ${ }^{9}$. El hombre deja de ser exclusivamente aquello que forma la sensibilidad empírica a golpes y desde el exterior, como pretendía Condillac con su ejemplo de la estatua: "ninguna cosa se asemeja menos a la naturaleza que aquellas estatuas a las que hacen sentir y obrar" (Cabanis, 1826, p. 95).

De Biran (1924), por su parte, ve precisamente en la experiencia de resistencia el hecho fundamental que presupone la motilité. Esto le permite afirmar que, al movernos (lorsque je me meus),

Soy yo quien se mueve o quien quiere moverse; y yo también yo quien soy movido. He aquí los dos términos de la relación que hacen falta para establecer el primer juicio simple de la personalidad: yo soy. No creo que se pueda encontrar el mismo fundamento en las impresiones pasivas. (p. 22) ${ }^{10}$.

Desde un punto de vista fenoménico que en su opinión complementa una falencia en la postura de Cabanis, afirma De Biran que "el yo se experimenta a sí mismo en sus operaciones" (Copleston, 2004, t. IV, p. IX-27). Para De Biran, y en general para toda esta generación de ideólogos, el yo de la motilité no es sustancial como en Descartes, no es una cosa diferente del cuerpo y anterior a la acción. El cógito, ergo sum no expresa una inferencia, sino una aprehensión intuitiva de un hecho primitivo o dato de conciencia del sentido íntimo. De Biran prefiere volo, ergo sum, "quiero luego existo" (Copleston, 2004, Vol. 4, p. IX-30). El esfuerzo voluntario que encuentra resistencias, esto es, la motilité, la acción,

9 «Le foetus a donc cette conscience du moi, car il a le besoin, le désir d'exécuter des mouvements » (Cabanis, 1815, p. lxxxix). Broussais opina de manera diferente. Para este, el movimiento del feto es "instintivo" y por tanto no involucra el yo o la voluntad.

$10 \ll$ ¿'est moi qui meus, ou qui veux mouvoir; et c'est encore moi qui suis mu. Voilà bien les deux termes du rapport nécessaires pour fonder ce premier jugement simple de personnalité je suis. Je ne crois pas qu'on pût retrouver le même fondement dans les impressions absolument passives. » 
permite el surgimiento de la percepción o consciencia, y al hacerlo revela el yo; y al revelar el yo, define el yo soy existencial. Yo soy es yo me muevo y yo me muevo es yo quiero moverme, donde el yo se percibe también como agente causal del movimiento, siempre y cuando este movimiento sea "reacción voluntaria" a una sensación o impresión percibida por el "centro cerebral" de la cual el yo tiene conocimiento.

Si bien con algunas reservas de su parte, De Biran asume con Cabanis y De Tracy, y en nuestro caso también lo hacen Broussais y José Eusebio Caro, que "el yo reside precisamente en la voluntad"11. Por supuesto, la motilité, el esfuerzo voluntario que encuentra resistencias, es "continuo durante la existencia vígil" (Copleston, 2004, p. IX-28), lo que permite la unidad temporal del yo.

\section{La facultad fisiológica de sentir y el análisis de la voluntad}

Para José Eusebio Caro, la voluntad es la causa de las acciones, en el entendido de que toda acción, en tanto movimiento espontáneo, es voluntaria, toda acción es una acción del yo. Ahora, el proceso mental de la imaginación y de la memoria (el recuerdo) le parecen también actos voluntarios, pero al ser mentales no ostentan movimiento corporal físico. Esto le hace ampliar la concepción de acción a "efecto de la voluntad sea o no movimiento" (Caro, 2002, p. 178) ${ }^{12}$.

Caro (2002) se pregunta por la filiación entre voluntad y acción y por los alcances de la influencia de la voluntad en la facultad del movimiento humano general. A lo primero su respuesta es: "la ignoramos. Solo sabemos que el músculo se contrae. Que el nervio está excitado. Nada más. Conjeturas” (p. 178),

11 La frase textual es de Cabanis (1815): “le moi réside exclusivement dans la volontê" (p. lxxxix). De Biran (1924) cita exactamente el mismo fragmento y pide al lector remitirse tanto a los Éléments d'idéologie de De Tracy, como a los Rapports du physique et du moral de Cabanis. A renglón seguido, asegura que los "kantianos" exponen el mismo principio: "Muchos kantianos enuncian el mismo principio casi de la misma forma, aunque en un sentido absoluto e indeterminado" [ «plusieurs kantistes énoncent le même principe à peu près sous la même forme, quoique dans un sens plus absolu et plus indéterminé. »] (p. 180).

12 En el pequeño esbozo que Caro (2002) dejó de la parte II de la Mecánica social, también se refiere al movimiento voluntario en los siguientes términos: "los movimientos voluntarios son internos o que acompañan a las impresiones, atenciones, recordaciones, e imaginaciones, o externos que son esfuerzos de movimientos, esfuerzos de quietud" (p. 281). 
en alusión a Cabanis, quien responde a la pregunta en términos de filiación sensación-movimiento. A lo segundo, responde Caro (2002): "los movimientos externos son rara vez involuntarios [...]. Los movimientos interiores son involuntarios, son infinitos, la mayor parte no sentidos. Los movimientos que hacen una sensación no dependen de nuestra voluntad" (pp. 197-198), aludiendo a Broussais ${ }^{13}$.

Respecto de la facultad de sentir, afirma Caro (2002) que la reconocemos en nosotros por experiencia propia y en los otros por analogía fisiológica, procedimiento similar al "descubrimiento" de la voluntad (p.186).

Las sensaciones, por su parte, las clasifica Caro en externas e internas ${ }^{14}$, y las divide en agradables, dolorosas o indiferentes ${ }^{15}$. Las sensaciones en esta teoría están referidas a la fisiología individual, lo que implica que su clasificación en externas o internas no es epistemológica, en el sentido de la proveniencia o dirección del

13 “xxxv. [...] Las percepciones del centro cerebral de que el Yo no tiene conocimiento y los movimientos que determina sin la participación del Yo, no se refieren ni a la sensibilidad ni a la voluntad. Son una especie particular de fenómenos orgánicos. El aparato nervioso cerebral presenta, pues, dos modos en sus funciones”. Esta es la mecánica animal o vegetal que presenta Caro. Por otra parte, contra la opinión de Cabanis, Broussais (1824) sostiene: "XLIII. Los actos solicitados por el instinto se ejecutan con frecuencia sin la participación del $Y o$, y aun en su ausencia. El feto, el sueño, etc., dan ejemplos de esto" (pp. ix, xi).

$14 \mathrm{Al}$ respecto dice Cabanis (1815): "es cierto que recibimos impresiones que nos vienen del exterior y otras que vienen del interior. Usualmente tenemos conciencia de aquellas; la mayoría de las veces ignoramos estas, y, por lo tanto, la causa de los movimientos que ellas determinan." [ « il est certain que nous recevons des impressions qui nous viennent de l'extérieur, et d'autres qui viennent de l'intérieur. Nous avons ordinairement la conscience des unes; le plus souvent, nous ignorons les autres, et par conséquent la cause des mouvemens qu'elles déterminent. »] (p. XLII). Por su parte, afirma Broussais (1827): “XIII. Los tejidos que se pueden considerar como los móviles naturales de las simpatías son aquellos que se encuentran en la materia nerviosa bajo una apariencia pulposa entremezclada con los vasos capilares sanguíneos, y con otros que contienen fluidos albuminosos o gelatinosos: estos pues son la piel y los sentidos de la cabeza que llamamos externos, y lo son también las membranas mucosas que son los sentidos internos" (p. iii).

15 Esta es la misma clasificación que hace Charles Comte (1826) respecto de los actos y las instituciones humanas en su Traité de législation: "todas las acciones y las instituciones se ubican necesariamente en estas tres clases: muchas son generalmente cosideradas útiles al género humano, otras son condideradas funestas, y otras dudosas o indeiferentes. " [ « toutes les actions et les institutions humaines rentrent nécessairement dans ces trois classes: plussieurs sont généralement considérées comme utiles au genre humain, d'autres sont considérées come funestes, et d'autres comme douteuses ou comme indifférentes. »] (p. 80). Charles Comte toma la clasificación de Bentham. 
dato empírico. Las sensaciones son externas cuando involucran sentidos externos como la piel, y son internas cuando involucran órganos internos, como las vísceras. Es desde este punto de vista que las divide Caro en dolorosas o agradables. Este tipo de sensaciones no necesitan de la competencia del yo para generar movimientos, pero son las que revelan el yo prioritariamente, en la medida en que el yo buscará con mayor consciencia repetir o sofocar placeres y penas.

Las sensaciones indiferentes son propiamente las percepciones, aquellas de las cuales el yo tiene completo conocimiento, y se diferencian de las sensaciones agradables o dolorosas, según Caro (2002), por el hecho de pintar "en la mente los objetos o cualidades", lo que los hace "más parecidos a sus recuerdos", y por formar "los materiales de la mayor parte de nuestros juicios" (p. 187). Para Caro, los juicios y los recuerdos son percepciones, es decir, sensaciones indiferentes, que sin embargo pueden estar acompañadas de sensaciones agradables o dolorosas ${ }^{16}$.

Ahora, en el análisis de la voluntad, encuentra Caro (2002) que está compuesta de volición, referida al esfuerzo voluntario del movimiento, y de deseo, relacionado con la sensación, la idea de la sensación o el recuerdo de la sensación. Exclusivamente, las sensaciones que son objeto de los deseos son las de "placer y no sensación de dolor" (p. 187), esto es, las sensaciones agradables. De entrada, advierte Caro que el deseo que interviene en la acción voluntaria es deseo de sensación placentera.

Caro no distingue muy claramente volición de voluntad; en ciertas partes asegura que son lo mismo y en otras afirma que la primera "modifica" la segun$\mathrm{da}^{17}$. No obstante, siempre recalca la diferencia entre voluntad y deseo. Si bien

$16 \mathrm{Al}$ respecto dice Broussais (1827): "Xv. Todo estímulo capaz de procurar al cerebro una percepción recorre todo el conjunto del sistema nervioso de relación. La acción va pues a repetirse en las membranas mucosas, de donde es aún vuelta al centro de percepción que la juzga según el aviso de la víscera a que pertenece la membrana mucosa; y que se determina a la acción según el placer o el dolor que percibe. Y esta acción tiene siempre por objeto hacer durar y repetir la impresión, o desviar su causa" (p. iv).

17 La modificación es un término muy usado por los ideólogos. Se refiere particularmente a la afección que produce cada sensación y que precisamente revela la actividad del yo, esto en contra de la pasividad de la estatua de Condillac. De Tracy (1804) afirma: "Cuando siento sensaciones o recuerdos son modificaciones que experimento. No afectan a nadie más que más que a mi” [« quand je sens des sensations, ou des souvenirs, ce sont des modifications que jéprouve. Elles n'affectent quà moi. »] (p. 73). Para Cabanis (1815), cuando el feto "nace, su cerebro, organo central en el que reside la 
no se puede tener volición sin deseo, esto es, sin idea alguna de la sensación querida, se puede desear sin tener volición, se puede tener el recuerdo o idea de la sensación sin que esta impulse aún el movimiento. Para que el deseo despierte la volición, que es la encargada de impulsar el movimiento, serán necesarios los juicios, percepciones inseparables e incluso, junto a los recuerdos, determinantes causalmente de los deseos.

Según Caro, los ideólogos confunden frecuentemente estas dos partes de la voluntad, lo que en su teoría significa que confunden la idea de la sensación y los juicios sobre su consecución (deseo), con el movimiento que la hace presente (volición).

Los deseos también tienen su causa: el interés. Caro (2002) concibe el interés como "un placer que se encuentra en una sensación agradable o en la no sensación de una sensación desagradable" (p. 180); y tienen un motivo: la sensación placentera ya sentida, lo que en la mente no puede ser más que el recuerdo o la idea presente de tal sensación. Motivo y deseo, como se ve, comparten definición, de suerte que para Caro "el motivo del deseo es el deseo mismo" o mejor una "modificación del deseo" (p. 182).

Todas las sensaciones, afirma Caro, son la percepción de la percepción, puesto que se encuentran siempre acompañadas de un juicio: que la sensación se conseguirá o no de nuevo.

Lo que se desea, es decir, el interés del deseo o su objeto, es sentir en el futuro la sensación placentera de la cual tenemos ya una idea o recuerdo, los cuales son el motivo del deseo, y ese deseo viene acompañado del juicio de la probabilidad de éxito. Juicio que, a su vez, trae consigo una sensación agradable o desagradable, diferente en todo caso a la sensación motivo del deseo. El juicio es una idea de sensación interna, identificable, dice Caro, con el temor o la esperanza. Como la sensación es una percepción (si es conocida por el yo, si no es instintiva, según

voluntad general, ha recibido ya modificaciones que le permiten salir de los simples apetitos del institnto" [ « arrive à la lumière [son cerveau] organe central, où réside la volonté générale, a déjà reçu des modifications qui commencent à le faire sortir des simples appétits de l'instinct. »] (p. lxxxix). Según De Biran (1922), "cada movimiento, cada paso dado es una modificación particular que me afecta doblemente, por ella misma y por el acto que la determina”. [ « chaque mouvement, chaque pas fait est une modification très distincte qui m'affecte doublement, et par elle-même et par l'acte que la détermine. »] (p. 22). 
los ideólogos) y el juicio que la acompaña es siempre una "modificación" de la percepción (Caro, 2002, p. 185), las sensaciones se convierten en percepción de la percepción.

Caro (2002), en consecuencia, amplía la definición de motivo: "un motivo (de deseo) es siempre un raciocinio", donde el raciocinio vendría siendo "una serie de juicios" (p. 183). Es decir, el motivo ya no es solo la sensación sentida, sino la sensación más los juicios sobre su consecución exitosa. Por eso dice Caro que el juicio "modifica el deseo", como lo hace también con las sensaciones, según se mencionó antes.

$\mathrm{Al}$ recuerdo lo define Caro (2002) como la "representación del [placer de la] sensación pasada", y la imaginación como "el recuerdo" que "algunas veces se hace sensación presente". El autor afirma que el recuerdo, cuando es voluntario, es también una percepción de la percepción (pp. 184-185).

\section{Las facultades humanas y la doctrina de la "futuridad del motivo"}

HaY, SEgún JosÉ Eusebio CARO, seis facultades en el ser humano: de la sensación, del recuerdo, del juicio, del deseo, de la voluntad de la acción y de la acción. Es una recapitulación de los Éléments d'idéologie de Destutt de Tracy (1804).

No poseería el hombre facultad alguna especial que cree objetos nuevos en la mente por medio de la combinación de ideas.

Si hay en el hombre una facultad particular que combinando nuestras ideas nos presente objetos nuevos [sic]. No la hay. Esa facultad no es más que la memoria dependiente de la voluntad, se la llama simplemente imaginación cuando no está sujeta y ordenada por la voluntad hacia un cierto fin predeterminado e invención cuando se dirige a un objeto preestablecido (Caro, 2002, p. 185).

Es sumamente interesante este aparte, ya que Caro contradice a De Tracy. Para el francés, la idea de un objeto percibido no existe más que como idea compuesta en nuestra mente, dado que lo que sentimos es una cantidad de ideas simples conjugadas por la acción conjunta de las diversas facultades intelectuales. A esta acción De Tracy (1804) la llama precisamente "concretar" (concraire), neologismo de su invención con el que busca referirse a la acción opuesta de "abstraer" (abstraire) (p. 88). 
De aquí se desprende una doctrina que reclama José Eusebio Caro (2002) como de su autoría y que llama la futuridad del motivo: el interés causa de los deseos es "un interés futuro", ya sea "placer o supresión de pena" (p. 200). El hombre no desea un placer que no conoce y mucho menos se mueve para buscar algo que no existe (podríamos decir, de lo cual su yo no tiene una percepción y mucho menos un juicio). "Todo deseo va dirigido a un interés -placer futuro-. La volición va dirigida al movimiento que debe transformar este interés en bien -placer presente-" (p. 187). Caro, como se ve, identifica bien con placer. Cuando el placer es futuro, cuando del placer solo se tiene una idea o recuerdo, este placer es interés. Cuando el placer es presente, cuando se siente efectivamente, este placer es un bien. Lo importante, entonces, es que el recuerdo se transforme en acto. El bien recae en la satisfacción de los deseos cuando tal satisfacción implica un movimiento voluntario. Pero este movimiento no se genera si el deseo no es despertado por una idea que ya se tiene, por una sensación y/o percepción del yo. Nada más puede mover voluntariamente al hombre, y recordemos que por movimiento Caro reconoce también los actos de la memoria y la imaginación. Por esto no se presentan objetos nuevos en la mente por medio de la combinación de ideas. Esta combinación sería un movimiento mental (imaginación o invención, es decir, la "memoria dependiente de la voluntad") pero el objeto nuevo traería consigo una sensación no experimentada previamente por los sentidos internos o externos, lo que anularía justamente el movimiento.

Para que el hombre se mueva, según José Eusebio Caro (2002), la volición debe estar causada por: "1. El interés conocido; 2 . El deseo de este interés (llamado motivo); 3 . El juicio de que tal acción producirá el placer; y 4 . El juicio de que esta acción es posible (para el sujeto voliente [sic.])” (pp. 187-188).

8. El influjo mutuo de las facultades humanas y la generación de ideas: la mecánica del movimiento voluntario o acción.

La “Generación de nuestras ideas”, según Caro (2002), no es más que el influjo "recíproco y sucesivo que van ejerciendo unas facultades sobre las otras" (p. 189). Así, la facultad de sensación influye sobre la facultad del recuerdo, el recuerdo sobre el juicio, el juicio sobre el deseo, el deseo sobre la voluntad de acción y esta sobre la acción. A partir de estas influencias reciprocas, la mecánica 
del movimiento voluntario o acción configura un proceso causal en el que las sensaciones o percepciones causan los recuerdos; los recuerdos y las sensaciones o percepciones causan los juicios; los juicios causan los deseos; los deseos causan las voliciones y las voliciones causan los actos.

Para Caro (2002) el carácter de la influencia recaerá en "la intensidad, duración y facilidad con que la facultad influyente obra sobre la facultad influida" (p. 189). Si la sensación o percepción es fuerte, intensa y duradera, permanecerá más tiempo en el recuerdo, y si el deseo es fuerte, intenso y duradero, y sus juicios son claros (es decir, verdaderos), despertará con mayor energía la volición. La acción cuya causa es una volición fuerte, intensa y duradera, es prácticamente una acción ejecutada.

El influjo de las sensaciones sobre los deseos, dice Caro (2002), es lo que "con alguna vaguedad llama Bentham valor de un placer o de una pena" (p. 190). Bentham (1991, p. 58) también llama a este valor precisamente la fuerza del placer o pena.

La repetición de un acto permite que una facultad influya sobre otra con suficiente facilidad. A esta facilidad de influencias da Caro el nombre de hábito. El hábito trae consigo como uno de sus efectos el crear necesidades facticias, las cuales pueden traducirse en movimientos poderosos de la voluntad ante el despertar de un deseo causado por la presencia de una sensación dolorosa. Incluso, advierte Caro, lo que despierta el deseo con más vehemencia, moviendo con igual ímpetu a la voluntad, es la sensación presente de pena, a despecho incluso de la búsqueda futura de placer o de supresión futura de dolor.

Estas consideraciones sobre la necesidad y el hábito están relacionadas con el instinto, de la manera en que Cabanis y Broussais lo plantearon, así como con la generación de vicios. En aquellos autores, instintivo es todo movimiento causado por una impresión o sensación no percibida por el yo. Para Caro las necesidades obran en el individuo sin volición, sin el juicio de que la acción es causa de la supresión de la pena. De cierta manera, podríamos decir que en las necesidades los juicios no "modifican" el deseo, lo que produce el proceso inverso a la toma de conciencia del acto. Estos actos se vuelven instintivos, independientes del yo, lo que hace a los vicios tan difíciles de erradicar. Estos movimientos no voluntarios, asegura Caro, pueden incluso obrar contra la volición y contra el deseo. 
9. La conclusión de la teoría de la voluntad de José Eusebio Caro: una libertad restringida

Lo interesante de toda esta mecánica fisiológica es la conclusión de Caro sobre la libertad. Para este, el término libertad se toma en dos sentidos: 1) poder satisfacer nuestros deseos; y 2) poder ejecutar nuestra voluntad. En realidad, son lo mismo, pues la ejecución de la voluntad no es más que la plena satisfacción de los deseos, si de ellos se tiene un juicio verdadero. El hombre es libre cuando, ya habiendo conocido los efectos de una acción, es decir, el bien que tal acción le proporciona, escoge la causa adecuada para que la mecánica del movimiento voluntario funcione correctamente.

Pero no es libre el hombre, según Caro, para obrar o no obrar o para querer o no querer. El querer o no querer hacen parte del deseo y esto solo podría suprimirse en la medida en que no hubiese actividad en el hombre. Todo hombre que actúe, a menos que su movimiento sea involuntario, instintivo, lo hace por su voluntad, es decir, por la combinación de deseo y volición. También afirma Caro que hay casos en que, aun ejecutando su voluntad, el hombre no es libre, pero solo plantea la situación sin desarrollar el punto.

10. Conclusión

BASTAN UNAS POCAS OBjECIONES para socavar los fundamentos de la teoría de la voluntad de José Eusebio Caro. Podría citarse la circularidad en la que cae el esquema de la acción voluntaria o el estado de inmediatez moral en la que deja al hombre. No actuamos para conseguir cualquier clase de placer, o para encontrarlo en el camino. Actuamos para conseguir "este" o "aquel" placer, un placer ya conocido y por lo tanto buscado conscientemente; un placer deseado. No hay contingencias en el proceso, porque de ser así, el mecanismo falla, el deseo no se satisface y la acción fracasa. En consecuencia, todo acto ha de estar sustentado de antemano por la sensación que es objetivo de la voluntad, o no habría acto. En pocas palabras, la voluntad se causa a sí misma.

Respecto de la inmediatez moral, Caro nos muestra que la moralidad de los actos radica precisamente en el conocimiento del medio que permite llegar al fin y no en el fin mismo. La benevolencia y el humanitarismo en esta moral tendrían 
dificultades. De cierta manera, esto nos sitúa en el mismo dilema de Hume, puesto que será muy difícil hacer salir del interés del yo el acto moral. Para universalizarlo, esto es, para poder juzgarlo a priori, Hume (2002) debió recurrir al principio psicológico de la simpatía.

Lo que encontramos aquí es un muy claro ejemplo de los obstáculos que imponía el contexto mecanicista en el que se desarrollaron este tipo de teorías. $\mathrm{Si}$ consideramos hombre y sociedad como máquinas, nos toparemos tarde o temprano con el callejón sin salida que el joven Caro advirtió y a partir del cual abandonó la pretensión de desarrollar una ciencia de la moral y la legislación: la máquina reproduce, pero no puede crear nada nuevo (Collingwood, 2006). Esta ciencia no podrá ofrecer a la sociedad principio moral alguno y es, en consecuencia, una teoría estéril. Es frustrante para Caro renunciar al juicio moral a priori por conservar la objetividad científica, más aún cuando tal renuncia le quita utilidad práctica a la ciencia de la moral y le cede a la religión y a la "sanción popular" la instrucción y juicio de los actos conscientes. Por eso prefiere retornar al catolicismo, como buena parte de los pensadores colombianos del siglo XIX, tal y como lo advirtió Eduardo Camacho Guizado (1984)

En la figura de Caro se puede ver ejemplarmente el ansia, la curiosidad, el "malestar de la cultura" de un pueblo joven que despierta, que interroga con patético entusiasmo juvenil, que descubre, que se equivoca, que se aventura libremente por el pensamiento heterodoxo de la época, pero que al fin regresa a la tradición, a los valores consagrados de su clase. Esa, en mayor o menor grado, es la trayectoria de la mayor parte de los intelectuales de este período, así como la de la historia nacional que, después de las aventuras liberales, regresa a los cauces del tradicionalismo católico y conservador" (tomo II, pp. 624-625).

Pero el concepto de hombre ya se encuentra para el siglo XIX irremediablemente modificado: ya no es sustancia material sino una máquina compuesta de órganos y nervios. Miguel Antonio Caro (1962), a pesar de adherir a la escuela espiritualista, intenta conciliar la fisiología con la religión: "con la luz de la religión, con los datos de la fisiología, el entendimiento descubre maravillosas conexiones entre el alma, cuya existencia garantiza la primera, y el cuerpo, cuyas leyes examina la segunda” (pp. 106, 577-578). 
El problema respecto del sustento más idóneo para la reorganización social luego de la Independencia se traslada de nuevo a la reflexión sobre la moral, ya que el nuevo concepto de hombre la modifica significativamente. El Caro más adulto, abanderado del pensamiento conservador, creerá advertir en la moral científica, individualista, utilitarista y liberal la consecuencia que luego retomará su hijo: la anarquía moral que desajusta un supuesto orden social. Apenas cuatro años después de redactar su Mecánica social, en un artículo de 1840 titulado Sobre educación pública en la Nueva Granada, responde Caro (1873) finalmente a su antiguo profesor, el doctor José Ignacio de Márquez, ahora presidente de la República, respecto del debate sobre la ética utilitarista:

Las causas de nuestras revueltas [se refiere a la Guerra de los Supremos, 18391842] son tres: la irreligiosidad, la inmoralidad, y el hambre, que toman su común origen, hasta cierto punto, en nuestro detestable sistema de educación que nos ha enseñado a discutir, no a trabajar; a buscar la utilidad, no a practicar la virtud, a creer en la materia y a negar a Dios. Y este detestable sistema de educación viene de la administración Santander que lo introdujo, y de la vuestra, señor, [se dirige a José Ignacio de Márquez] que lo ha conservado" (p. 78).

Referencias

Bauman, Z. (2002). La cultura como praxis. Madrid: Paidós.

Bentham, J. (1991). Antología. Barcelona: Ediciones Península.

Beorlegui, C. (2006). Historia del pensamiento filosófico latinoamericano. Bilbao: Deusto.

de Biran, M. (1924). CEuvres. París: Librairie Féliz Alcan.

Broussais, V. (1827). Principios de la medicina fisiológica, y examen de la anatomia patológica y de algunas doctrinas nuevas. Madrid: Imprenta de Don Pedro Sanz.

Bushnell, D. (1985). El régimen de Santander en la gran Colombia. Bogotá: El Áncora Editores.

Cabanis, G. (1815). Rapports du physique et moral de l'homme. París: Chez Béchet jeune, libraire de la Académie Royale de Médicine. 
Cabanis, G. (1826). Relaciones de lo fisico y moral del hombre. París: Imprenta de J. Smith.

Camacho, E. (1984). "La literatura colombiana entre 1820 y 1900". En: Jaramillo, J. (Dir.). Manual de historia de Colombia (t. II, pp. 613-693). Bogotá: Instituto Colombiano de Cultura.

Caro, J. E. (1873). Obras escogidas en prosa y en verso publicadas e inéditas de José Eusebio Caro ordenadas por los redactores de el Tradicionista. Bogotá: Imprenta y librería de "el Tradicionista".

Caro, J. E. (2002). Mecánica social o teoría del movimiento humano considerado en su naturaleza, en sus efectos y en sus causas. Bogotá: Instituto Caro y Cuervo.

Caro, M. A. (1962). Obras. Bogotá: Instituto Caro y Cuervo.

Collingwood, R. G. (2006). Idea de la naturaleza. Ciudad de México: Fondo de Cultura Económica.

Comte, A. (2001). Primeros ensayos. Ciudad de México: Fondo de Cultura Económica.

Comte, C. (1826). Traité de législation ou exposition des lois générales suivant lesquelles les peuples prospèrent, dépérissent ou restent stationnaires. París: A Sautelet et C. ie, libraires, Place de la Bourse.

Comte, C. (1836). Tratado de lejislación o esposición de las leyes jenerales con arreglo las cuales prosperan, decaen o se estancan los pueblos. Barcelona: Imprenta de don Antonio Bergnes, calle de Escudellers, n. 39.

Copleston, F. (2004). Historia de la filosofía. Barcelona: Ariel.

Dussel, E., Mendieta, E., \& Bohórquez, C. (2011). El pensamiento filosófico latinoamericano, del Caribe y "latino". 1300-2000. Ciudad de México: Siglo XxI Editores.

Gélvez, R. (2017). El positivismo de José Eusebio Caro en la Mecánica social: un viejo error en la historiografía colombiana. Anuario Colombiano de Historia Social y de la Cultura, 44(1), 259-277. doi: 10.15446/achsc.

Guerra, F. (1993). Modernidad e independencias. Ciudad de México: Fondo de Cultura Económica.

Hume, D. (2002). Tratado de la naturaleza humana. Madrid: Tecnos.

Jaramillo, J. (2001). El pensamiento colombiano en el siglo XIX. Bogotá: Alfaomega.

Larroyo, F. (1989). La filosofía iberoamericana. Ciudad de México: Porrúa. 
Lefranc, J. (2011). La philosophie en France au XIXe siècle. París: L'Harmattan. López, L. (1990). Obra educativa de Santander. 1835-1837. Bogotá: Biblioteca de la Presidencia de la República.

Saether, S. (2005). Identidades e independencia en Santa Marta y Riohacha, 1750-1850. Bogotá: Instituto Colombiano de Antropología e Historia.

Say, J. B. (1816). Tratado de economía politica (vol. 1). Madrid: Imprenta de Collado.

Silva, R. (2008). Los ilustrados de Nueva Granada. 1760-1808. Medellín: EAfit. Sosa, G. (2006). Representación e independencia. 1810-1816. Bogotá: Instituto Colombiano de Antropología e Historia / Fundación Carolina.

de Tracy, D. (1804). Éléments d'idéologie. Idéologie proprement dite. París: Chez Courcier, Imprimeur-Libraire pour le Mathématique.

de Tracy, D. (1830). Elementos de ideología. Caracas: Imprenta de Valentín Espinal. 